\title{
Interactive comment on "Modeling land surface processes over a mountainous rainforest in Costa Rica using CLM4.5 and CLM5" by Jaeyoung Song et al.
}

\section{Anonymous Referee \#2}

Received and published: 11 June 2020

Please see attached documet for complete review.

Please also note the supplement to this comment: https://www.geosci-model-dev-discuss.net/gmd-2019-335/gmd-2019-335-RC2supplement.pdf

Interactive comment on Geosci. Model Dev. Discuss., https://doi.org/10.5194/gmd-2019-335, 2020. 